\title{
Spectrum of Endoscopic Findings in Patients of Upper Gastrointestinal Bleeding at a Tertiary Care Hospital
}

Waseem Sarwar Malghani ${ }^{1}$, Romaisa Malik ${ }^{1}$, Farooq Mohyud Din Chaudhary ${ }^{1}$, Asim Tameez Ud Din $^{2}$, Misbah Shahid ${ }^{1}$, Sultan Ahmad ${ }^{1}$, Asma Tameez Ud Din ${ }^{3}$, Sana Mohyud Din Chaudhary ${ }^{4}$

1. Gastroenterology, Nishtar Medical University \& Hospital, Multan, PAK 2. Internal Medicine, Rawalpindi Medical University, Rawalpindi, PAK 3. Internal Medicine, Nishtar Medical University \& Hospital, Multan, PAK 4. Internal Medicine, Combined Military Hospital Lahore Medical College \& Institute of Dentistry, Lahore, PAK

$\square$ Corresponding author: Farooq Mohyud Din Chaudhary, farooqmdc@gmail.com Disclosures can be found in Additional Information at the end of the article

\section{Abstract}

\section{Background \& aims}

Upper gastrointestinal bleeding (UGIB) is a common medical emergency that results in high patient morbidity and mortality. There are numerous causes of UGIB. The aim of our study was to evaluate the endoscopic findings in patients of UGIB in this part of the world.

\section{Methods}

This retrospective study was conducted at the Department of Gastroenterology Nishtar Medical University \& Hospital Multan from June 2018 to March 2019. Record of all patients undergoing esophagogastroduodenoscopy (EGD) for evaluation of UGIB was reviewed. Data was entered and analyzed using SPSS version 20 (IBM, Armonk, NY, USA).

\section{Results}

Record of 730 (464 male and 266 females) patients undergoing EGD for UGIB was reviewed. Mean age of study population was 49.38 years with standard deviation of 14.86 years. Age of the youngest patient was 14 years while the oldest patient was 99 years of age. More than half of the patients (53\%) belonged to the 41-60 years age group. The most common endoscopic finding was esophageal varices in 371 (50.8\%) patients, followed by gastropathy (114, 15.6\%), gastritis $(68,9.3 \%)$, cardio-fundal varices $(58,7.9 \%)$ and duodenal ulcer (26, 3.6\%). Esophageal varices, gastritis, duodenal ulcers and gastric carcinomas were more likely to be found in male

Received 04/22/2019 Review began $04 / 23 / 2019$ Review ended 04/24/2019 Published 04/29/2019

\section{(c) Copyright 2019}

Malghani et al. This is an open access article distributed under the terms of the Creative Commons Attribution License CC-BY 3.0., which permits unrestricted use, distribution, and reproduction in any medium, provided the original author and source are credited. UGIB patients as compared to female patients $(\mathrm{p}=0.039)$. Gastropathy, esophageal ulcer and gastric ulcer were more likely to be found in female UGIB patients. Esophageal varices and cardio-fundal varices were more likely to be found in UGIB patients from middle age group $(\mathrm{p}=$ 0.000). Whereas gastritis, duodenal ulcer, gastric erosions and duodenitis were more likely to be found in older (>60 years) UGIB patients $(\mathrm{p}=0.000)$.

\section{Conclusion}

UGIB was more likely to occur in male gender. In our study, bleeding from esophageal varices was the most important cause of UGIB in this part of the world and bleeding from duodenal ulcer was quite uncommon as compared to the western world. Variceal bleeding had a significant association with male gender and middle age group patients. While duodenal ulcer 
Categories: Gastroenterology

Keywords: esophageal varices, upper gastrointestinal bleeding, esophageal varices, esophagogastroduodenoscopy, endoscopic findings, peptic ulcer

\section{Introduction}

Upper gastrointestinal bleeding (UGIB) is a very common and serious medical problem encountered in the Accident and Emergency Department of hospitals around the world. This condition has a high mortality of around 5-15\% [1,2] and therefore requires immediate resuscitation and intervention. It is more common in males as compared to females. However, the mortality rate is equal in both genders [3]. UGIB occurs when the bleeding site is proximal to ligament of Treitz. Hematemesis or blood in vomitus is the presenting complaint in $40-50 \%$ cases of UGIB [4]. In approximately $80 \%$ of patients bleeding stops spontaneously without any intervention. In the rest of patients who continue to bleed, they have a high rate of mortality and require intervention to stop the bleeding.

There is a long list of causes that result in upper gastrointestinal bleeding. Prominent causes include peptic ulcer disease (PUD), bleeding esophageal varices, esophagitis and gastric and duodenal erosions. There are some less common causes of UGIB as well. These include Dieulafoy's lesions, angiodysplasia, aorto-enteric fistula and hemobilia. Bleeding from esophageal varices is a very important cause of UGIB which has a high morbidity and mortality. Esophageal varices are found in lower one-third of esophagus as abnormally dilated submucosal veins. These usually occur as a result of cirrhosis-related complication of portal hypertension [5]. In this region of the world, bleeding from the esophageal varices is the commonest cause of UGIB [6]. This contrasts to the western world where peptic ulcer disease is more common.

Esophagogastroduodenoscopy (EGD) is an indispensable tool in establishing the cause and site of bleeding in patients of UGIB. It also has the advantage of permitting therapeutic interventions like endoscopic variceal band ligation for bleeding varices, clipping and adrenaline injection for bleeding peptic ulcers and biopsies of any suspicious looking area. The purpose of our study was to ascertain the different causes of UGIB in this part of the world.

\section{Materials And Methods}

This retrospective study was carried out at the Department of Gastroenterology Nishtar Medical University \& Hospital Multan after approval from the Institutional Ethical Review Committee of Nishtar Medical University Multan. This study included all patients referred to endoscopy room from both the hospital's own wards as well as the surrounding hospitals and clinics from June 2018 to March 2019. UGIB was labeled if a patient had complaints of hematemesis or of passing tarry black stools (melena). EGD was performed in 730 patients after resuscitation and consent by a consultant gastroenterologist having at least three years post fellowship experience. EGD was performed in the endoscopic room under lignocaine gargles.

Data regarding demographics (age, gender) and endoscopic findings were collected. Data were then entered into SPSS version 20 (IBN, Armonk, NY, USA). Statistical data analysis was performed with chi-square. Statistical significance was determined at $p<0.05$. Information obtained was then analyzed according to age, gender and endoscopic findings and presented in form of tables. 


\section{Cureus}

\section{Results}

Our study was comprised of 730 patients who presented with UGIB, of which 464 (63.6\%) were males and 266 (36.4\%) were females. Male to female ratio was 1.7:1. Mean age of study population was 49.38 years with standard deviation of 14.86 years. Mean age of males was 49 years while that of females was 50 years. Age of the youngest patient was 14 years while the oldest patient was 99 years of age. Maximum number of patients $(n=203)$ belonged to the fifth decade of life. More than half of the patients (53\%) who had UGIB belonged to the 41-60 years age group (Table 1).

\section{Characteristics}

Age (years)

Mean

Standard Deviation

Range

Gender

Male

Female

Age Groups (years)

$<40$

$41-60$

$>60$
N (\%)

$137(18.8)$

TABLE 1: Demographic features of patients presenting with UGIB $(N=730)$.

UGIB: Upper gastrointestinal bleeding.

Table 2 shows the endoscopic findings in patients of UGIB in our study. The most common endoscopic finding was esophageal varices which occurred in more than half of the patients who had UGIB ( $\mathrm{n}=371)$. The second most common endoscopic finding after esophageal varices was portal hypertensive gastropathy which was seen in 114 (15.6\%) patients. This was followed, in decreasing order of frequency by gastritis $(68,9.3 \%)$, cardio-fundal varices $(58,7.9 \%)$, duodenal ulcer (26, 3.6\%) and other rarer causes (Table 2). While comparing the distribution of endoscopic findings with respect to gender, esophageal varices, gastritis, duodenal ulcers and gastric carcinomas were more likely to be found in male UGIB patients as compared to female patients $(\mathrm{p}=0.039)$. Gastropathy, esophageal ulcer and gastric ulcer were more likely to be found in female UGIB patients. 


\section{Cureus}

\begin{tabular}{|c|c|c|c|}
\hline \multirow{2}{*}{ Endoscopic findings } & \multicolumn{2}{|l|}{ Gender $^{*}$} & \multirow{2}{*}{ Total (\%) } \\
\hline & Male $(\%)^{* *}$ & Female $(\%)^{* *}$ & \\
\hline Esophageal varices & $245(52.8)$ & $126(47.4)$ & $371(50.8)$ \\
\hline Gastropathy & 60 (12.9) & $54(20.3)$ & 114 (15.6) \\
\hline Gastritis & $47(10.1)$ & $21(7.9)$ & $68(9.3)$ \\
\hline Cardio-fundal varices & $37(8.0)$ & $21(7.9)$ & $58(7.9)$ \\
\hline Duodenal ulcer & $20(4.3)$ & $6(2.3)$ & $26(3.6)$ \\
\hline Esophageal ulcer & $9(1.9)$ & $9(3.4)$ & $18(2.5)$ \\
\hline Gastric ulcer & $8(1.7)$ & $10(3.8)$ & $18(2.5)$ \\
\hline Gastric erosions & $8(1.7)$ & $6(2.3)$ & $14(1.9)$ \\
\hline Duodenitis & $8(1.7)$ & $5(1.9)$ & $13(1.8)$ \\
\hline Gastric tumour & $11(2.4)$ & $1(0.4)$ & $12(1.6)$ \\
\hline Esophageal erosions & $5(1.1)$ & $5(1.9)$ & $10(1.4)$ \\
\hline Esophagitis & $3(0.6)$ & $0(0)$ & $3(0.4)$ \\
\hline Dieulafoy's lesion & $1(0.2)$ & $2(0.8)$ & $3(0.4)$ \\
\hline Esophageal tumour & $2(0.4)$ & $0(0)$ & $2(0.3)$ \\
\hline
\end{tabular}

\section{TABLE 2: Distribution of endoscopic findings in UGIB patients and its frequency with}

gender $(\mathrm{N}=730$, male $=464$ and female $=266)$.

${ }^{*} p=0.039$ comparing endoscopic findings between male and female patients.

** percentages within gender.

UGIB: Upper gastrointestinal bleeding.

Table 3 depicts the distribution of endoscopic findings with respect to age of patients. Esophageal varices and cardio-fundal varices were more likely to be found in UGIB patients from middle age group $(\mathrm{p}=0.000)$. While gastritis, duodenal ulcer, gastric erosions and duodenitis were more likely to be found in older ( $>60$ years) UGIB patients $(p=0.000)$. 


\section{Cureus}

\begin{tabular}{|c|c|c|c|c|}
\hline \multirow{2}{*}{ Endoscopic findings } & \multicolumn{3}{|c|}{ Age of the patients ${ }^{*}$} & \multirow{2}{*}{ Total N (\%) } \\
\hline & $<40$ years $\mathrm{n}(\%)^{* *}$ & $41-60$ years $n(\%)^{* *}$ & $>60$ years $\mathrm{n}(\%)^{\star *}$ & \\
\hline Esophageal varices & $92(44.7)$ & $220(56.8)$ & $59(43.1)$ & $371(50.8)$ \\
\hline Gastropathy & 28 (13.6) & $63(16.3)$ & $23(16.8)$ & $114(15.6)$ \\
\hline Gastritis & $33(16.0)$ & $17(4.4)$ & $18(13.1)$ & $68(9.3)$ \\
\hline Cardio-fundal varices & $14(6.8)$ & $38(9.8)$ & $6(4.4)$ & $58(7.9)$ \\
\hline Duodenal ulcer & $9(4.4)$ & $9(2.3)$ & $8(5.8)$ & $26(3.6)$ \\
\hline Esophageal ulcer & $8(3.9)$ & $9(2.3)$ & $1(0.7)$ & $18(2.5)$ \\
\hline Gastric ulcer & $7(3.4)$ & $7(1.8)$ & $4(2.9)$ & $18(2.5)$ \\
\hline Gastric erosions & $5(2.4)$ & $5(1.3)$ & $4(2.9)$ & $14(1.9)$ \\
\hline Duodenitis & $2(1.0)$ & $5(1.3)$ & $6(4.4)$ & $13(1.8)$ \\
\hline Gastric tumour & $3(1.5)$ & $3(0.8)$ & $6(4.4)$ & $12(1.6)$ \\
\hline Esophageal erosions & $3(1.5)$ & $6(1.6)$ & $1(0.7)$ & $10(1.4)$ \\
\hline Esophagitis & $1(0.5)$ & $1(0.3)$ & $1(0.7)$ & $3(0.4)$ \\
\hline Dieulafoy's lesion & $0(0.0)$ & $3(0.8)$ & $0(0.0)$ & $3(0.4)$ \\
\hline Esophageal tumour & $1(0.5)$ & $1(0.3)$ & $0(0.0)$ & $2(0.3)$ \\
\hline
\end{tabular}

\section{TABLE 3: Causes of upper gastrointestinal bleeding in different age groups $(N=730)$.}

${ }^{*} p=0.000$ comparing endoscopic findings among different age groups.

${ }^{* *}$ percentages within age groups of patients.

\section{Discussion}

In our study, patient presenting with UGIB had a mean age of 49.38 years. This was slightly lower as compared to mean age of UGIB patients reported in western studies [7,8]. This may depict higher ratio of older population in western world. In our study, UGIB was more common in male patients as compared to females, with a male to female ratio of $1.7: 1$. This was comparable to the data reported in western studies in which male patient ratio was greater than females $[2,9]$.

The most common and important etiology of UGIB found in our study was bleeding from esophageal varices (50.8\%). Other causes of UGIB included portal hypertensive gastropathy, gastritis and gastric erosions. Peptic ulcer is more common than esophageal varices in western world. However, the endoscopic findings of peptic ulcer (gastric and duodenal ulcer) were only found in $6.1 \%$ of patients in our study. Similar results were reported in local and international studies as well [10-12]. In contrast to our study findings, several other studies showed peptic 
ulcer disease as the most common cause of UGIB [13-16].

High prevalence of esophageal varices in our population may be due to the high prevalence of viral hepatitis (Hepatitis B and C) related cirrhosis. Comparable results to our study are also found in other local studies as well. In a local study, 53\% of cases had esophageal varices and $20 \%$ had peptic ulcer disease [17]. In our study, portal hypertensive gastropathy was the second most common cause of UGIB while in another local study, 64\% of cases had esophageal varices and gastric erosions were the second most common cause, i.e., erosive gastritis $15 \%$ and PUD $10 \%$ of cases [18].

There were some limitations in our study. As our study was carried out at a tertiary care centre, it may not be representative of the general population. Many patients with milder symptoms may not report to the hospital. Also, this was a single center study. Another important thing is that as our hospital is a government run setup, patients mostly belonging to low socioeconomic status come here. Multicenter studies targeting clinics providing EGD services should also be taken into account in future studies to further improve our understanding of different etiologies of UGIB.

\section{Conclusions}

It is very essential to have a basic understanding of different conditions causing UGIB. Our study showed that male patients were more likely to present to emergency department with UGIB. Bleeding from esophageal varices was the most important cause of UGIB and bleeding from duodenal ulcer was quite uncommon as compared to the western studies. Esophageal varices, gastritis, duodenal ulcers and gastric carcinomas were more likely to be found in male UGIB patients. Conversely, female UGIB patients were more likely to have findings of gastropathy, esophageal ulcer and gastric ulcer on EGD. Variceal bleeding was more likely to be found in middle age patients. While gastritis, duodenal ulcer, gastric erosions and duodenitis were more likely to be found in older patients.

\section{Additional Information \\ Disclosures}

Human subjects: Consent was obtained by all participants in this study. Institutional Ethical Review Committee, Nishtar Medical College \& Hospital, Multan issued approval Diary No. 12805 dated: 24-12-2018. Approval for this retrospective study was obtained from the Institutional Ethical Review Committee, Nishtar Medical College \& Hospital Multan. Animal subjects: All authors have confirmed that this study did not involve animal subjects or tissue. Conflicts of interest: In compliance with the ICMJE uniform disclosure form, all authors declare the following: Payment/services info: All authors have declared that no financial support was received from any organization for the submitted work. Financial relationships: All authors have declared that they have no financial relationships at present or within the previous three years with any organizations that might have an interest in the submitted work. Other relationships: All authors have declared that there are no other relationships or activities that could appear to have influenced the submitted work.

\section{Acknowledgements}

We would like to acknowledge the hard work and effort of whole team of Endoscopic Suite, Department of Gastroenterology, Nishtar Medical University \& Hospital Multan.

\section{References}

1. Alema ON, Martin DO, Okello TR: Endoscopic findings in upper gastrointestinal bleeding 
patients at Lacor hospital, northern Uganda. Afr Health Sci. 2012, 12:518-521.

2. Rockall TA, Logan RF, Devlin HB, Northfield TC: Incidence of and mortality from acute upper gastrointestinal haemorrhage in the United Kingdom. BMJ. 1995, 311:222. 10.1136/bmj.311.6999.222

3. Longstreth GF: Epidemiology of hospitalization for acute upper gastrointestinal hemorrhage: a population-based study. Am J Gastroentrol. 1995, 90:206-210.

4. Lirio RA: Management of upper gastrointestinal bleeding in children: variceal and nonvariceal. Gastrointest Endosc Clin N Am. 2016, 26:63-73. 10.1016/j.giec.2015.09.003

5. Ahmed A, Ali L, Shehbaz L, Nasir S, Rizvi SRH, Aman MZ, Ali Z: The prevalence of acute upper gastrointestinal bleeding and the factors causing hemorrhage as observed at a tertiary health care centre in Karachi, Pakistan. Pak J Surg. 2017, 33:36-40.

6. Hadayat R, Jehangiri AU, Gul R, Khan AN, Said K, Gandapur A: Endoscopic findings of upper gastrointestinal bleeding in patients with liver cirrhosis. J Ayub Med Coll Abbottabad. 2015, 27:391-394.

7. Theocharis GJ, Thomopoulos KC, Sakellaropoulos G, Katsakoulis E, Nikolopoulou V: Changing trends in the epidemiology and clinical outcome of acute upper gastrointestinal bleeding in a defined geographical area in Greece. J Clin Gastroenterol. 2008, 42:128-133. 10.1097/01.mcg.0000248004.73075.ad

8. Zaltman C, Souza HS, Castro ME, Sobral M de F, Dias PC, Lemos V Jr: Upper gastrointestinal bleeding in a Brazilian hospital: a retrospective study of endoscopic records. Arq Gastroenterol. 2002, 39:74-80. 10.1590/S0004-28032002000200002

9. Mustapha SK, Ajayi N, Jibrin YB, Shehu A: Aetiology of upper gastrointestinal bleeding in North-Eastern Nigeria: a retrospective review of endoscopic findings. Nigerian J Gastroenterol Hepatol. 2009, 1:75-78.

10. Dewan KR, Patowary BS, Bhattarai S: A study of clinical and endoscopic profile of acute upper, gastrointestinal bleeding. Kathmandu Univ Med J. 2014, 12:21-25. 10.3126/kumj.v12i1.13628

11. Suba M, Ayana SM, Mtabho CM, Kibiki GS: The aetiology, management and clinical outcome of upper gastrointestinal bleeding among patients admitted at the Kilimanjaro Christian Medical Centre in Moshi,Tanzania. Tanzan J Health Res. 2010, 12:302-305.

10.4314/thrb.v12i4.51073

12. Sarwar S, Dilshad A, Khan AA, Alam A, Butt AK, Tariq S, Ahmad I: Predictive value of Rockall score for rebleeding and mortality in patients with variceal bleeding. J Coll Physicians Surg Pak. 2007, 17:253-256. 05.2007/JCPSP.253256

13. Botianu A, Matei D, Tantau M, Acalovschi M: Mortality and need of surgical treatment in acute upper gastrointestinal bleeding: a one year study in a tertiary center with a 24 hours / day-7 days / week endoscopy call. Has anything changed?. Chirurgia (Bucur). 2013, 108:312318.

14. Singh SP, Panigrahi MK: Spectrum of upper gastrointestinal hemorrhage in coastal Odisha . Trop Gastroenterol. 2013, 34:14-17.

15. Gurung RB, Joshi G, Gautam N, Pant P, Pokhrel B, Koju R, Bedi TR: Upper gastro-intestinal bleeding: aetiology and demographic profile based on endoscopic examination at Dhulikhel hospital, Kathmandu University Hospital. Kathmandu Univ Med J. 2010, 8:208-211. 10.3126/kumj.v8i2.3560

16. Gaudong Mbethe GL, Mounguengui D, Ondounda M, et al.: Epidemiology of upper gastrointestinal bleeding in Gabon. (Article in French). Med Sante Trop. 2014, 24:441-443. 10.1684/mst.2014.0376

17. Pasha MB, Hashir MM, Pasha AK, Pasha MB, Raza AA, Fatima M: Frequency of esophageal varices patients with upper gastrointestinal bleeding. Pak J Med Sci. 2011, 27:277-281.

18. Shah MA, Butt Z, Younis I, Afzal M, Atta H, Nadir A: Etiology of upper gastrointestinal bleed at Aziz Bhatti Shaheed Teaching Hospital Gujarat. Ann Pak Inst Med Sci. 2016, 12:80-84. 